\title{
A TRIBUTE TO JEAN PERRIN
}

_ Henk Kubbinga - University of Groningen (The Netherlands) - DOI: 10.1051/epn/2013502

Nineteenth century's physics was primarily a molecular physics in the style of Laplace. Maxwell had been guided by Laplace's breathtaking nebular hypothesis and its consequences for Saturn. Somewhat later Van der Waals drew upon his analysis of capillarity. The many textbooks of Biot perpetuated the molecularism involved in all this. Jean Perrin, then, proposed a charmingly simple proof for the well-foundedness of the molecular theory (1908). 
J ean [Baptiste] Perrin enrolled in 1891 at the Ecole Normale Supérieure de Paris, the nursery of France's academic staff. The new 'normalien' came from Lyon and had passed a typically French parcours: primary school and collège 'en province', lycée at Paris. The 'normaliens' of the time were left-winged politically, but wore uniforms, though, and despised their Sorbonne fellow students. Mathematics made the difference; Perrin had passed without any trouble. He was lucky to follow in the footsteps of the great Marcel Brillouin (1854-1948), who had introduced Boltzmann's classical Vorlesungen über Gastheorie in France.

In preparing his doctorat ès sciences, Perrin made his international debute as a talented experimentalist in 1895 , when he published a straightforward demonstration that the charge of (the particles of) cathode rays is negative (Figure 1). With other work on Röntgen's new rays, it earned him in 1896 the Joule Prize of the Royal Society of London. What a start for this lad of scarcely 26 year of age!

\section{From physico-chemistry back to physics}

Perrin was charged with something new at the Sorbonne: a course of physico-chemistry, the new science that had been inaugurated by Van't Hoff, Ostwald and Arrhenius. It brought him to write down his lectures in the form of a textbook: 'Traité de chimie physique. Les principes' (1903). Among his friends were Pierre and Marie CurieSklodowska, his neighbours at Boulevard Kellermann, Paris, and Pierre Langevin, a former student of Pierre Curie. These were sober living people, not unlike the Perrins, Jean and his Henriette. They regularly met, mostly at the Perrins', where Jean often played the piano. The nature of the atom was hotly discussed on such occasions. Perrin weighted the solar system as a model-a positively charged 'sun' with negatively charged 'planets' around it-but didnot insist. An important turn came by a new invention, that of the ultramicroscope by Henry Siedentopf and Richard Zsigmundy (1903), an instrument which allowed for the first time to study the details of an age-old but still riddle-like phenomenon: Brownian motion. Discovered in the late 1820's by the English naturalist Robert Brown, the phenomenon implied the incessant, unperturbable zig-zag motion of tiny particles suspended in a liquid. In Brown's case there were pollen grains in water at stake. About 1903 it was a matter of what were called colloidal particles. The irregular motion also strongly reminded of a similar motion postulated in gas theory for the molecules describing their free paths between two collisions: the bigger the particles and/or the lower the temperature, the slower the motion. It was otherwise the time that Perrin had to answer pressing questions from Sorbonne's philosophers: "was it allowed, for a scientist, to make use of invisibly small particles like molecules (and atoms)?" Perrin's answer was a stroke of genius. He referred to the microbes of Louis Pasteur and Robert Koch and fancied a state of science in which the microscope had not yet been invented. In such a situation Pasteur and Koch-let's say, medical science in general-might have concluded all the same that contagious diseases were caused by invisibly small living beings which infect a victim and set out immediately to multiply, before attacking subsequent victims etc. Effective countermeasures might have been developed in that very same hypothesis, by trying all kinds of chemicals on infected materials. However, the microscope was there all the same and had hugely simplified the research. In the case of the molecules, though, the situation was quite the reverse: there was not yet a microscope to make them visible, but scientists had nonetheless succeeded in building an impressive whole of thoroughly consistent physics and chemistry, fully based on the idea of molecules composed of atoms. In our age of monomolecular if not monoatomic microscopy, it is easy to grasp the appropriateness of Perrin's reasoning.

\section{Brownian motion}

Siedentopf and Zsigmundy's invention opened new alleys to assess colloidal particles, among which gold granules dispersed in glass. But, irresistibly, Brownian motion, with its direct bearing on the hard core of contemporary physics, that is: the kinetic theory of gases, came to the fore. In 1905-1906 Einstein and Smoluchowski published their analyses. Einstein showed that the observed zig-zag route of colloidal particles could be deduced from what he called the 'molecular-kinetic theory of heat'. One of his arguments derived from the osmotic pressure to be expected from suspensions: after all, the only difference between dissolved molecules and suspended particles is their bigness. And hence, when molecules move haphazardly hither and thither, those particles should move in very much the same way, be it on a smaller scale. Something similar holds for diffusion. The translation and rotation of such particles ought to be analyzed, of course, in terms of Maxwell's statistical physics. In principle, then, the thermal velocity of any particle may be calculated in advance, provided that its mass is known and that it is in the gaseous state. Once suspended in a viscous liquid there is, of course, friction tending to slow down the particle. Application of the law of Stokes then allows for a quantitative evaluation. Marian Smoluchowski, in 1906, worked the other way around: he stressed the importance of the collisions between the liquid molecules and the suspended particles. Against this background Jean Perrin set out to experimentally investigate Brownian motion.

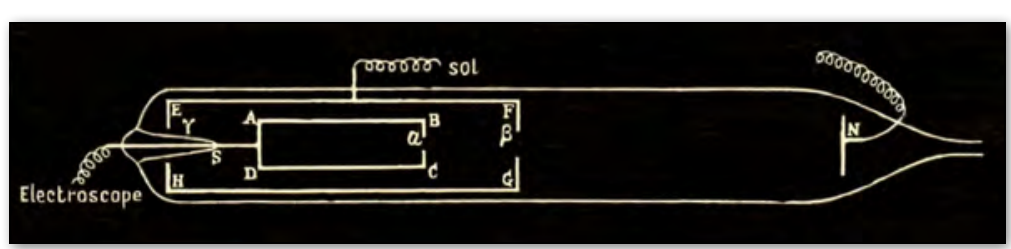

4 P.16: Saturn (with Titan) edge-on as viewed by the Hubble Telescope (2012; courtesy: NASA).

V FIG. 1: Perrin's demonstration of the negative charge of the particles involved in gas discharge tubes. $\mathrm{N}$ is the cathode; cylinder EFGH is the (earthened) anode. Through the openings $\beta$ and $\alpha$ the unperturbed pencil of cathode rays reaches the Faraday cylinder ABCD which is connected to a gold foil electroscope. With an electromagnet the pencil can be directed at FG, such that it doesn't reach $A B C D$. 


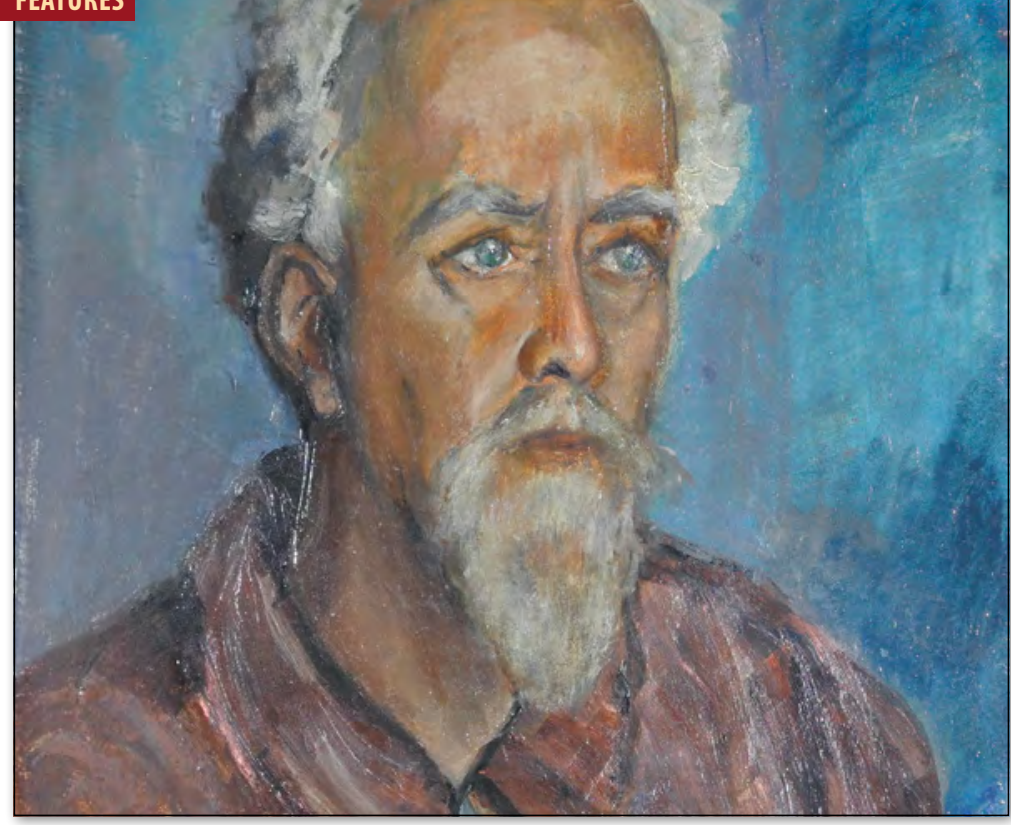

mole $\left(6.7 \cdot 10^{23}\right)$. Perfectly conscious of the importance of his find, Perrin took the liberty to call it after the Italian gas specialist Amedeo Avogadro (1776-1856).

\section{The new light: nothing but phyics}

In Perrin's work there is a direct link with Laplace's physics: both were essentially molecular. Perrin, however, did what Laplace had neglected: he found a new way to assess molecular dimensions. At the time the philosophers tried to mix in and impose their terminology, but in vain. Physics is self-sufficient: it provides for its own philosophy. Perrin's brilliant assessments earned him the Nobel Prize for Physics of 1926.

\section{Science and politics in the 1930's}

$\triangle$ FIG. 2: Jean Perrin by his daughter Aline

Lapicque-Perrin (oil on canvas; about 1926; courtesy Perrin family, Paris).

\section{Laplace, Perrin: granules and molecules} In his magnum opus Traité de mécanique céleste Laplace had deduced a formula for the observed decrease in air pressure with heigth. The essence was that that decrease would obey a logarithmic law: $\ln \left(p_{0} / p\right)=C \cdot h$. Constant $C$ in Laplace's formula had been checked by measuring the air pressure at the foot and on top of a duly famous mountain of known heigth, the Puy de Dome (Auvergne). It had allowed the first scientific 'aironauts', the ballooners Gay Lussac and Biot (1804), to calculate the heigth they had attained: $6977 \mathrm{~m}$ above Paris.

Perrin had noticed that resting suspensions of gamboge in water-let's say, in a test tube-because of sedimentation, feature a vertical colour intensity gradient, which reminded him of Laplace's logarithmic law. If the analogy between granules and molecules be correct, then, the number of granules should decrease as $\ln \left(n_{0} / n\right)=C \cdot h$. The new ultramicroscope of Zsigmundy and Siedentopf allowed him to test the formula: because of its weak focal depth Perrin could simply take photographs, count the number of granules in the field of view and follow its variation with heigth. The number of granules appeared to half every $10 \mu \mathrm{m}$. Wonderful! The analogy, then, was justified indeed. And, the other way around, since granules definitely exist, so do the molecules. Through his granules Perrin even succeeded in determining the number of molecules in a 'grammolecule', today's
Later,Perrin and his socialist compagnons joined the French government. It was Perrin who, as under-State Secretary of Scientific Research (1936-1938), imposed the creation of the Centre National de la Recherche Scientifique (CNRS) in an attempt to reinvigorate academic life at the top. In 1941, the war was raging, Perrin and his family moved to the United States, where he died the next year.

\section{About the author}

Henk Kubbinga is a historian of science at the University of Groningen and member of the EPS-History of Physics Group. He recently co-edited, with Paul Bronsveld, the Festschrift in honor of Jeff Th.M. De Hosson (Groningen University Press, 2012).

\section{Acknowledgment}

I am greatly indebted to Guy Laval, Foreign Secretary of the Académie des Sciences of the Institut de France, who kindly allowed me to consult the Archives of the Académie. Courtesy photographs: Académie des Sciences.

\section{References}

[1] J. Perrin, Comptes rendus de l'Académie des Sciences 121 1130 (1895)

[2] J. Perrin, Revue Scientifique 15, 449 (1901)

[3] J. Perrin, Annales de Chimie et de Physique (8 ${ }^{\text {th }}$ series) 18, 1 (1909)
- FIG. 3:

Drawings made after photographs taken at heights differing $10 \mu \mathrm{m} ;$ The mean diameter of the grains was $\mathbf{0 . 6}$ $\mu \mathrm{m}$ (from Ref. 3).

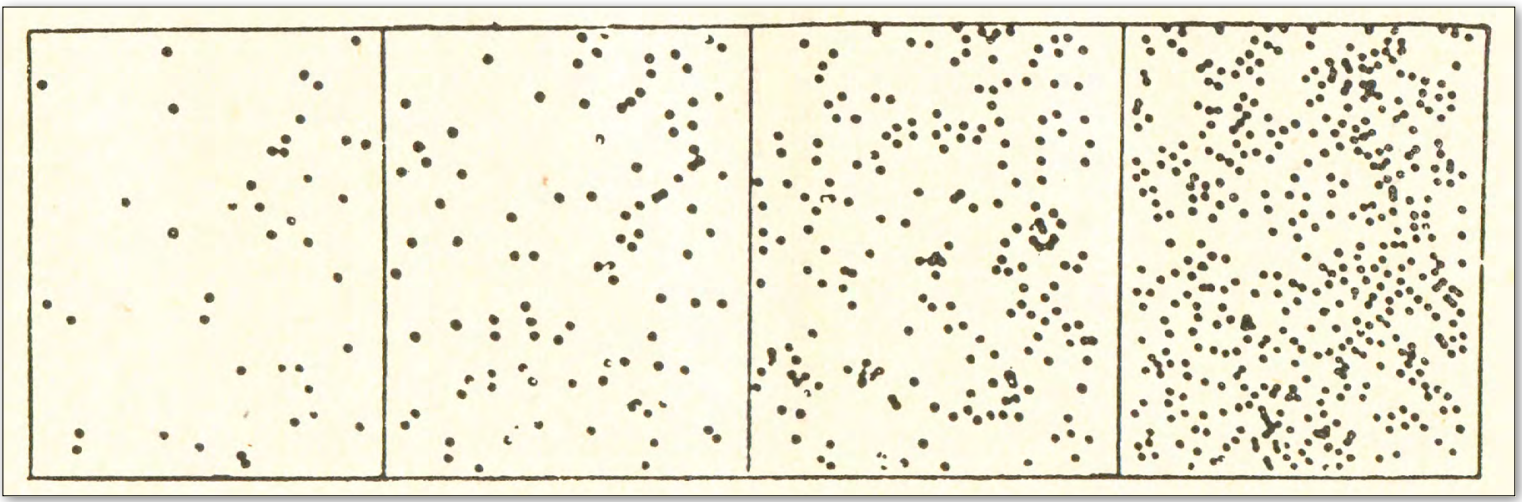

